\title{
Principios bioéticos en el contexto de la pandemia de COVID-19
}

\author{
Bioethical principles in the context of the COVID-19 pandemic \\ Cesar Ñique Carbajal 1,a,b, Mirtha Cervera Vallejos ${ }^{1, a, c}$, , Rosa Díaz Manchay 2,a,d, \\ Constantino Domínguez Barrera ${ }^{3, \mathrm{a}, \mathrm{e}}$
}

\section{RESUMEN}

El avance de la pandemia de COVID 19 a escala mundial ha desencadenado una crisis en los sistemas sanitarios que muchos países no han podido superar. En nuestro país incluso se ha visto afectada la relación entre los profesionales de las ciencias de la salud, los pacientes y sus familias, en parte inducida por un estado desorganizado, que al seguir lineamientos de otras realidades sobre el manejo de pacientes bajo ciertos estándares del estado de salud, se han estipulado normativas que influyen en el tratamiento y pronóstico de la vida de la persona afectada, observándose atentados contra la dignidad del ser persona, de igual forma el desabastecimiento de los recursos, la corrupción y la pobre capacidad resolutiva del diagnóstico viral, no solo han permitido que se desconozca en tiempo real la enfermedad en nuestro país, sino que ha conllevado al desánimo de los profesionales como médicos y enfermeras, quienes al brindar atención y cuidado, a la variedad de estos pacientes también experimentan incapacidad, y vulnerabilidad ante la pandemia. En este sentido creemos necesario repensar sobre el impacto de la pandemia en nuestra población, así como en nuestro sistema de salud, para lo cual es importante volver al estudio de la atención sanitaria, el cuidado humano integral, modelos o corrientes en bioética vigentes, principios éticos personalistas para su abordaje; con la finalidad de brindar unos lineamientos y recomendaciones a tener en cuenta en la gestión y practica biomédica ante la crisis causada por el SARS-CoV-2.

PALABRAS CLAVE: Bioética, infecciones por coronavirus, humanización de la atención, salud pública. (Fuente: DeCS BIREME).

\section{SUMMARY}

The worldwide spread of the COVID-19 pandemic has triggered an international sanitary crisis that many countries could not tackle. In our country the relationship among the health care professionals their patients and relatives has been affected, in part due to a disorganized governmental response to the pandemic that dictated incorrect treatment recommendations based on foreign experiences resulting in severe attempts against the individual dignity. On the other hand, the lack of resources, the rampant corruption and the poor resolution capacity for diagnosing cases

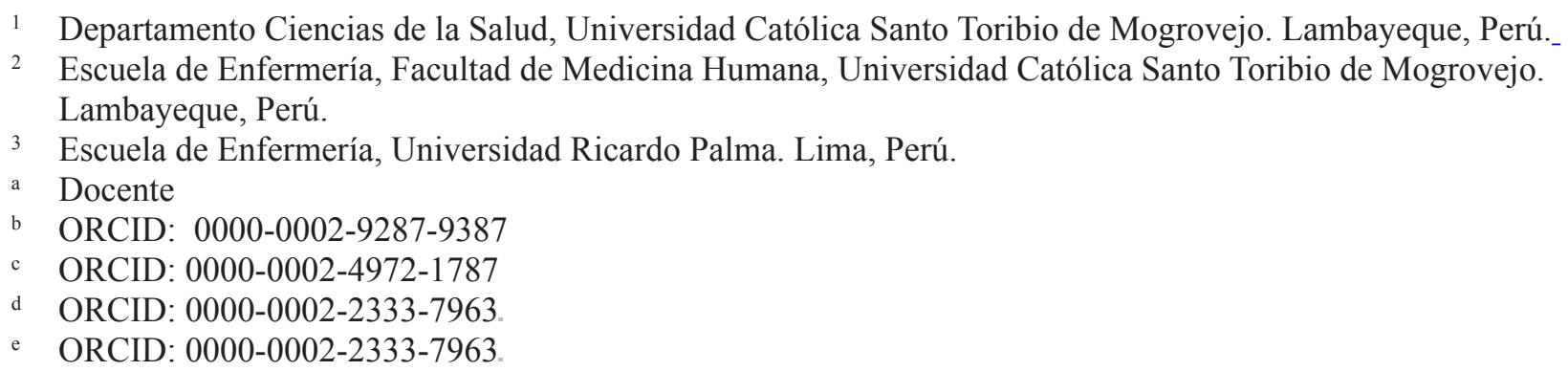


leaded not only of knowing the magnitude of the pandemic in the country but also to discouragement among health care professionals who are at the frontline experiencing fear and vulnerability. We do believe that we need to rethink on the impact of the pandemic in the country as well as on the critical reforms needed in our health care system promoting integrated human care, following current bioethical models and personalized ethical principles in order to improve current medical practices during the COVID-19 pandemic.

KEYWORDS: Bioethics, coronavirus infections, humanization of assistance, public health. (Source: MeSH NLM).

\section{INTRODUCCIÓN}

Desde el mes de diciembre del 2019 cuando se registró por primera vez algunos casos de neumonía de origen desconocido en Wuhan, provincia de Hubei (China) hasta la actualidad, la gran mayoría de países en el mundo han sido afectados por la COVID-19, causada por el nuevo coronavirus denominado SARS$\mathrm{CoV}-2$, adquiriendo la categoría de pandemia.

Este virus tiene tropismo por las células del epitelio respiratorio y se relaciona con una transmisión zoonótica proveniente de una especie de murciélago; cuando ingresa al ser humano puede progresar y complicar generando cuadros de neumonía en personas que presentan ciertas condiciones como edad avanzada y la presencia de comorbilidades. La infección del virus se da a través de la inhalación de aerosoles y el contacto con superficies, permitiendo que el contagio de persona a persona se facilite y en poco tiempo haya un aumento exponencial en el número de individuos infectados y complicados, los mismos que podrían saturar los servicios de salud generando un aumento en el número de fallecidos debido a la insuficiente cantidad y disponibilidad de camas con necesidades especiales, como las que se encuentran en las unidades de cuidados intensivos (UCI) en las instituciones de salud (1).

En el Perú la crisis por la COVID 19 abarca también otros ámbitos de la vida social como el político, económico, poblacional, y en el sector sanitario ha desnudado de manera cruda y real nuestra precariedad institucional encontrándose hospitales viejos, falta de materiales, de laboratorios especializados, de camas, de ventiladores mecánicos, de especialistas, y una población geriátrica abandonada, médicos no bien remunerados, sin seguro médico, y como nunca, falta de equipos de bioseguridad para combatir a este nuevo flagelo (2).
Es evidente que, para enfrentar a esta pandemia, no solo se requiere de un plan protocolizado y recursos materiales, sino también de un número adecuado de profesionales sanitarios que maximicen sus capacidades, para una práctica clínica que difiere en gran medida de la habitual, debido a cargas de trabajo extremas, con la capacidad para enfrentarse a nuevos dilemas morales. La perspectiva bioética basada en los derechos humanos y en una visión integral de la concepción de la persona humana en su estadio de paciente debería desempeñar un papel fundamental en el contexto de esta complicada pandemia. Ante este panorama se ha priorizado la atención a nivel comunitario, en actividades preventivas, empoderando al paciente y realizando labores epidemiológicas como la identificación de casos y la localización de sus contactos, sin despreocuparnos por los pacientes dados de alta, así como también brindando acompañamiento aquellos que se encuentran en el final de la vida, teniendo presente a la población más vulnerable, y todo esto sin olvidar la atención a demanda, el servicio de emergencias y nuestros pacientes crónicos (3).

En consecuencia, después de esta breve descripción sobre el efecto de la pandemia por COVID 19 en nuestro medio, el objetivo del artículo fue dejar acentuada la necesidad e importancia de reflexionar sobre los aspectos humanísticos y bioéticos de la práctica sanitaria, con énfasis en el cuidado humano integral, el análisis de los modelos bioéticos vigentes y la práctica de principios éticos en la atención sanitaria que se viven en nuestro medio. Es conveniente para ello empezar por definir algunos términos como: pandemia, atención sanitaria integral, cuidado humano, bioética y principios éticos del actuar biomédico sobre todo por ser una enfermedad que la comunidad científica empieza a comprender, y que requiere de un análisis reflexivo ante cada situación complicada de gestionar desde un solo enfoque o mirada, la observancia multidisciplinaria como lo exige el análisis bioético por el manejo interdisciplinar, pluralista y dialógico 
que tiene per se, ayudarían sin duda en este sentido, ya que esta se sustenta en el análisis de valores y virtudes que se operativizan en la práctica.

\section{El virus SARS-CoV-2 y la Pandemia}

El nuevo coronavirus es un virus constituido por un genoma tipo ARN monocatenario que presenta una alta tasa de mutación, lo cual aumenta la diversidad de especies virales y asimismo le confiere la capacidad de adaptarse rápidamente a nuevos hospederos. En el ser humano se ha determinado que la principal fuente de infección son los pacientes infectados por SARS$\mathrm{CoV}-2$ a través de las gotas respiratorias ( $>5$ micras) cuando los pacientes tosen, hablan o estornudan, de ahí que el contacto cercano se constituye en una fuente de transmisión $(1,4)$.

El virus SARS-CoV-2 presenta una envoltura lipoproteica que contiene las glicoproteínas virales que se proyectan hacia la superficie externa dando el aspecto de corona. Estas glicoproteínas son importantes para el proceso de infección del virus ya que se relacionan con el tropismo o afinidad por ciertos receptores celulares. La glicoproteína $\mathrm{S}$ tiene afinidad por el receptor de la ACE2 (enzima convertidora de angiotensina 2) que se expresa en células endoteliales de los vasos y en el epitelio pulmonar, de allí la posibilidad de que el virus afecte la vía aérea inferior. Los estudios de la estructura del virus han mostrado que hay una similitud en la secuencia del genoma del SARS-CoV-2 y el SARS-CoV1 en el 79,5\%, mientras que existe una similitud del genoma del SARS-CoV-2 con el del Coronavirus de murciélago RaTG13, en $96,2 \%$. Estos hallazgos han mostrado que la estructura y secuencia de la glicoproteína S del SARS-CoV-2 es diferente a la de la cepa SARS-CoV-1, pues tiene una afinidad 10 o 20 veces mayor por el receptor celular lo cual puede explicar la efectiva diseminación en poblaciones humanas $(1,4)$.

Desde los primeros casos reportados como neumonía de origen desconocido en Wuhan hasta la actualidad, el virus se ha expandido por todo el planeta, aproximadamente más de 180 países han sido afectados, siendo histórico el 11 de febrero del presente año, fecha en la que el Director General de la OMS declaró la situación de pandemia; sin duda alguna en el presente siglo la República popular de China será recordada como el lugar de origen de diferentes patógenos potenciales, especialmente agentes virales que han causado emergencia en el mundo. Entre ellos la gripe aviar en 1997, el síndrome respiratorio agudo severo (SARS) en 2003, el Síndrome de fiebre severa con trombocitopenia (SFTS) en 2010, y el reciente virus latente surgido en el sureste de China en Wuhan, provincia Hubei en diciembre del 2019 (5).

La emergencia de esta enfermedad, se ha explicado por el surgimiento de un nuevo coronavirus humano con incrementados factores de virulencia. El número exponencialmente creciente de casos en el mundo, refleja en parte la rápida transmisión del SARSCoV-2, alcanzando la etapa de propagación en la comunidad, dada la susceptibilidad del 100\% de la población mundial. Contar con datos detallados y precisos permitirá comprender y hacer un seguimiento del alcance de esta pandemia y fortalecer los esfuerzos de prevención y respuesta, en virtud que hasta el momento los tratamientos son experimentales y la vacuna podría estar disponible a mediano o largo plazo. Lo real es que el mundo se encuentra luchando arduamente en contra de la que quizás es la pandemia más severa a la que se haya enfrentado la humanidad. Esta lucha liderada por la OMS, gobiernos del mundo y respaldada por miles de científicos y personal de salud, quienes invaluablemente han ofrecido sus conocimientos y experiencia para el control de la pandemia con la finalidad de evitar más muertes. Las medidas de distanciamiento social y la cuarentena han sido claves para mitigar la pandemia y la respuesta de la población aislándose ha representado un importante sacrificio, pero conforme pasan las semanas ha demostrado un impacto significativo en el desarrollo positivo de la pandemia (6).

\section{Atención sanitaria integral de salud en el contexto de la pandemia de COVID-19}

La actual situación de salud, expresa el impacto de un momento del proceso de la pandemia de COVID-19, problema de larga data que nos muestra un presente caótico y un futuro indeterminado e incierto. Por esta razón, su estudio se sostiene en los fundamentos de la Salud Pública y su metodología (ciencia interdisciplinaria), que en nuestra realidad lógica "comunidad científica" no es considerada como "ciencia emergente" (7).De tal manera, el análisis crítico de la "situación de salud", pilar de la ciencia de Salud, se concibe como: "la posición relativa y conjunta, que adoptan sus componentes, en un momento determinado y espacio definido, entre los cuales describimos: a) el estado de salud, b) el sistema de servicios de servicios de salud (SSS) y c) los determinantes sociales; encontrándose en un permanente y constante proceso de establecer la 
atención integral de la salud colectiva en una sociedad" (8).

Ante este panorama, el análisis crítico, desde el enfoque sistémico método de la Teoría General de Sistemas (TGS), sostiene que la "totalidad organizada, hecha de elementos solidarios que pueden ser definidos como los entes que se encuentran en relación, es decir los unos con los otros en función de su lugar en esta totalidad"(9). Esto podría trasladarse al examen del "impacto de la pandemia Covid 19 en el sistema sanitario" donde se encuentra implícito la concepción de la TGS. Parafraseando el mito griego, observamos que el impacto ha determinado el destape de la "caja de pandora", pilar del Sistema Nacional de Salud (SSS) desde hace aproximadamente un cuarto de siglo; permitiendo identificar los elementos que no permiten la acción eficaz y eficiente, en esta línea de pensamiento, se determinan los obstáculos más significativos que dificultan e impiden la orientación y definición de las acciones sanitarias consistentes e inherentes; ejecutadas con eficiencia y eficacia en el marco de un SSS, factible y viable (10).

Por las razones expuestas, el análisis crítico de este componente de la situación de salud, se encuentra orientado por las concepciones de:

a) Impacto, en su acepción de "huella o efecto producidos por el choque del COVID-19 con la realidad de la sociedad del Perú.

b) Sector Salud (Sistema Nacional de Salud), que según Decreto Legislativo $\mathrm{N}^{\circ} 1161$ de fecha 06-diciembre-2013, a la letra se menciona: "El Sector Salud, está conformado por el Ministerio de Salud, como organismo rector, las entidades adscritas a él y aquellas instituciones públicas y privadas de nivel nacional, regional y local, y personas naturales que realizan actividades vinculadas a las competencias establecidas en la presente Ley, y que tienen impacto directo o indirecto en la salud, individual o colectiva".

Así el sector salud puede entenderse como el espacio social de confluencia de personas, organizaciones y entidades, que realizan actividades (todas o algunas de estas) relacionadas directamente con la salud individual o colectiva en el país, o que repercuten indirectamente en ella. De esta manera, dentro del sector salud se reconocen una gama diversa de actores sociales o grupos de interés que deben ser debidamente identificados. c) Los juicios de valor, que se establecen son de la comprensión inferencial de las Publicaciones de Análisis de Situación de Salud (ASIS) del Centro Nacional de Epidemiología - Prevención y control de Enfermedades - MINSA - PERU, proporcionan un panorama general de la situación de salud en el Perú de los últimos cinco años, a través del análisis de los determinantes socioeconómicos y sanitarios, su influencia en el estado de salud de la población y la respuesta social, identificando los grandes problemas existentes en nuestro país y realizando su priorización, con la finalidad de proporcionar conocimiento para la toma de decisiones en los diferentes niveles del sector.

d) Identificar los obstáculos más significativos que dificultan e impiden la orientación y definición de acciones sanitarias consistentes e inherentes; ejecutadas con eficiencia y eficacia en el marco de la factibilidad y viabilidad (10).

Ante estos considerandos podríamos inferir que nuestro sistema sanitario en el contexto de la pandemia viene mostrando que:

- La estructura, organización y funciones no implementan adecuadamente su doctrina, sustentada en los Artículos $7^{\circ}, 9^{\circ}, 11^{\circ}$ y $16^{\circ}$ de la Constitución Política del Perú (1993)

- Las politicas, formalizadas en la concepción de apoyo social, no tienen en cuenta la Carta de Ottawa (1998), la Declaración de Yakarta (1997), la Declaración de Shanghái (2016) y menos aún la Agenda 2030 para el Desarrollo Sostenible, cuyo objetivo principal es velar por la protección de las personas, el planeta y la prosperidad.

- La Organización, es fragmentada y desarticulada, por las diferentes políticas jurídica-administrativas de cada uno de los componentes institucionales, que no permiten el ejercicio eficiente de la Rectoría para establecer un sistema integrado por niveles de complejidad articulados por régimen de referencia y contrarreferencia en un modelo de atención integral de la salud individual y colectiva.

- Escasez de recursos, económicos, humanos y físicos, mal distribuidos y concentrados privilegiando a ciertos espacios socioeconómicos y políticos.

- Inadecuado perfil de producción por el elevado porcentaje de actividades de recuperación de la salud en todos los niveles y espacios sociodemográficos

- Deficiente productividad por difícil acceso a los servicios, determinada por las condiciones 
geográficas, económicas y culturales de la población.

- Cobertura deficiente y fragmentada de atención por falta de delimitación de la población asignada.

En este sentido nos preguntamos ¿Cómo se debe proceder ante tanta carencia y desorganización en la debida atención a los pacientes infectados por COVID-19 en nuestros centros de salud?, ¿Qué principios éticos debe manejar el profesional biomédico para enfrentarse a la pandemia? Son válidos estos cuestionamientos con la finalidad de ofrecer un trato digno en correspondencia a su esencia como ser persona, en el cuidado humano integral, dada las dificultades y precariedad de nuestro sistema sanitario.

\section{Cuidado humano en un paciente con COVID-19}

Cuando nos referimos al cuidado humano, es equiparable a la preocupación auténtica por el "otro" e incluye la amabilidad en aquellas acciones tan "simples y milenarias" que hacen la diferencia al lidiar con el dolor, la ansiedad, la angustia, el sentimiento de pérdida, el temor de lo desconocido y tantos otros sentimientos que acometen al paciente y a su familiar en situaciones de vulnerabilidad. Para ello, los cuidadores de la salud en especial el personal de enfermería debe ofrecer un cuidado que proporcione confort, no solo de orden físico, sino también espiritual, utilizar técnicas de relajamiento, la escucha activa, el silencio, el toque terapéutico, la mirada cariñosa, pueden ser el hecho diferencial; y a veces, la tecnología y el lenguaje técnico que los profesionales de salud emplean, les hace fallar en percibir que las pequeñas cosas o simples detalles son más importantes para que el paciente se sienta cuidado, como, por ejemplo, un masaje, peinar los cabellos, cepillarle los dientes, mojarle la boca, moverle en la cama, tocarle con cariño (11).

En tiempos de pandemia el cuidado humano se ha visto afectado sin lugar a dudas por el exceso de pacientes, el miedo intrínseco que causa esta enfermedad por su alta contagiosidad, la escasez de equipos de protección y aquellos miembros del equipo que pueden usarla, parecen "robots", no se les puede identificar quienes son, son testigos presenciales del dolor e incertidumbre que repara el sufrimiento de las personas más vulnerables al sentir impotencia y ver morir a numerosos pacientes cada día al extremo de ser denominadas como experiencias desgarradoras (12), todo ello unido a las largas jornadas laborales que llevan a cabo por la escasez de personal de salud, ya sea porque fueron contagiados y ahora son pacientes que deben estar aislados en sus respectivos hogares, o simplemente porque renunciaron por el miedo de contagiar a su propia familia.

En nuestro país la pendiente de contagios ha ido en aumento y los casos de infectados en nuestro medio se ha descontrolado, el sistema sanitario peruano ha colapsado, sobre todo cuando los pacientes tienen falla respiratoria y requieren el uso de ventilación asistida en las unidades de cuidados intensivos (13). El Estado ha hecho su mejor esfuerzo en designar hospitales para atender estos casos, pero el personal de salud sigue de pie a pesar de la escasez de equipos de protección, exponiendo su salud, su vida y posiblemente poniendo en peligro a sus familiares, y deben sopesar la opción de continuar trabajando o pedir licencia, aunque no sea remunerada (14). En general, el equipo de salud tiene la obligación de atender a los pacientes, incluso si esto los pone en riesgo, pero los deberes para con los pacientes a veces pueden verse limitados por los deberes para con los demás. Al mismo tiempo, los hospitales tienen obligaciones correlativas para proteger a sus empleados y mitigar el riesgo, equilibrar estas tareas requiere sopesar los beneficios y riesgos, a menudo en el contexto de una considerable incertidumbre (15)

Cuando hablamos de cuidado humano también debemos fijar nuestra atención y mirada en el equipo de salud, quien como han denominado muchos se encuentra en "pie de guerra", ya que se enfrentan día a día con la muerte sabiendo que se va perdiendo la batalla, observando también atentados contra familiares y amigos en el momento de atender los enfermos por COVID-19 sin tener las medidas de protección adecuadas, el práctico suicidio que se realiza por la misma situación, la presión social de tener que servir por "vocación" normalizando la explotación laboral, y el aumento de la carga tanto laboral, como emocional y académica, puede orillar al personal de salud a un punto de quiebre mental, del cual si no se toman medidas preventivas ahora, terminará con consecuencias funestas a futuro (16).A su vez, las mujeres que trabajan en este sector no dejan por ello de tener a su cargo personas dependientes o que necesitan cuidados en sus hogares: deben seguir asistiendo a sus trabajos con esta responsabilidad, lo que aumenta sus sobrecargas de trabajo y estrés (17).

Como resultado del rápido incremento de casos confirmados y muertes, la población general y el personal de salud experimentan problemas psicológicos, como ansiedad, depresión y estrés (18). 
No obstante, también debemos reflexionar sobre el modo de facilitar un entorno más compasivo en el morir de estos pacientes, y procurar el oportuno acompañamiento de un ser querido en el momento de la muerte, así como el apoyo espiritual o religioso cuando lo soliciten, es un esfuerzo a todas luces justificado y un acto superior de humanización, obviamente con todas las medidas necesarias de bioseguridad (19).

¿Cómo humanizamos la atención de salud hacia el final de la vida en este contexto? Se conoce que el cadáver de una persona con el virus continúa contagiando, por ello las personas fallecidas no pueden ser despedidas, mueren solas, ni veladas y se sugiere la cremación, avasallando en este caso hasta los cultos religiosos (20). Es necesario que la atención en los momentos finales de su vida sea con la mayor calidad asistencial y humana posible, que, de acuerdo con la filosofía de los cuidados paliativos, incluyen criterios de atención psico-emocional, espiritual, religioso y de acompañamiento familiar, pues todos ellos contribuirán a evitar duelos patológicos y al agravamiento de las situaciones de vulnerabilidad (19).

Es así, que esta pandemia ha suscitado ansiedades y temores sustanciales para los trabajadores de la salud, y muchas de las técnicas habitualmente empleadas por el personal de salud para brindar comodidad a los pacientes y sus familias se vuelven más difíciles o imposibles de implementar. Junto con el virus ha proliferado el miedo, la ansiedad y la incertidumbre para lo cual sería importante retomar o centrarse en las mejores prácticas que rodean comunicación, empatía y compasión. Esto puede ayudar a rebrotar el humanismo en la atención de pacientes con COVID-19 $(21,22)$. Frente a ello, el desafío del equipo de salud será no deshumanizarse en esta pandemia, buscar redactar protocolos de actuación que contemplen el trato humanizado en este contexto, que se evalúe el caso concreto, sobre la base de los pilares de la Bioética, de la dignidad del ser humano, del trato digno al paciente desde una perspectiva de derechos humanos (20).

\section{Corrientes en Bioética y manejo de los pacientes con COVID 19}

La enciclopedia de Bioética de Reich (23), en el año 1978 define a la bioética como el "estudio sistemático de la conducta humana en el ámbito de las ciencias de la vida y de la salud, analizados a la luz de los valores y principios morales", valoración sin duda de tipo ético porque califica la bondad o maldad del actuar humano el cual debe realizarse a la luz de un determinado sistema de referencia; análisis que aplica a los siguientes escenarios: a) todo lo relativo a las cuestiones de valor que se plantean a los profesionales de la salud; b) la investigación biomédica y a la del comportamiento independientemente de que tengan o no implicaciones terapéuticas; c) cuestiones sociales relacionadas con la salud pública que van desde la salud en el mundo al control de los nacimientos y d) la vida animal y vegetal; básicamente considerando los principios éticos sobre el respeto a la vida humana, que pertenece al orden de la objetividad y debe servir de finalidad a la actuación ética, y la autodeterminación de la persona, que remite al dominio de la subjetividad $y$ es esencial en la ética.

Actualmente existen diferentes modelos éticos de referencia práctica, con muy desiguales consecuencias y jerarquías de valores a la hora de evaluar cualquiera de las cuestiones debatidas y sobre todo a la hora de enfrentarse con los dos principios de la bioética comentadas en el párrafo anterior: el respeto a la dignidad de la vida humana y la defensa de la libertad de la persona, estos modelos o corrientes se encuentran enfocados desde perspectivas de valoración muy distintas, con la consecuencia de que, partiendo de los mismos principios, se lleguen a conclusiones muy diferentes, e incluso difícilmente compatibles entre sí, estableciendo diversos cuerpos de doctrina. Se reconocen al menos cuatro tal como se muestra en la tabla 1: el modelo liberal radical, el pragmáticoutilitarista, el socio-biológico y el personalista $(24,25)$.

Teniendo como argumentos una definición de bioética que implica valorar nuestra conducta en el debido actuar ante los pacientes con COVID 19 y los diversos enfoques conceptuales que operan hoy en día en la práctica biomédica, consideramos que el prototipo que ofrece una protección y defensa de la vida humana y de la libertad como paradigmas de la ética del cuidado humano integral que venimos analizando, en contraste con el impacto que viene causando la pandemia trascendiendo la afectación a nivel individual para alcanzar la afectación a nivel familiar y social, sin duda seria la visión personalista, aquella corriente que nos brinda mayores fundamentos ontológicos y antropológicos para el debido actuar ante conflictos éticos donde la bioética amerita actuar, resaltando su importancia y recordándonos la parte más humana de nuestro quehacer como profesionales de las ciencias de salud. Este modelo se ampara en la formulación de cuatros principios éticos: a) Principio de defensa de la vida física; b) principio de totalidad; c) 
Tabla 1. Características de las corrientes en bioética (25).

\section{Corrientes en Bioética Características}

Liberal-radical

Pragmático-utilitarista

Socio biológico

Personalista
Cuyo marco de referencia y suprema del juicio ético es la libertad: es lícito lo que es libremente querido, libremente aceptado y no daña la libertad de los demás. Este modelo realza un aspecto fundamental de la referencia ética, que es el valor de la libertad. Este es un valor que todos debemos defender, y en el que este modelo pone la prioridad. Las conclusiones de este modelo en la vida cotidiana, tal y como se suele aplicar, serían: la liberalización del aborto, la elección del sexo de los hijos, el cambio de sexo por parte del que lo desee, la libre actuación en la fecundación «in vitro», la libertad de decidir el momento de la propia muerte. La principal debilidad de este método está en que, desde un punto de vista estrictamente ético, al establecer una jerarquía de valores es evidente que hay valores que anteceden a la libertad. Por ejemplo, el derecho a la vida antecede a la libertad: todo acto libre lo es de un hombre que actúa libremente. Sin vida humana, no es posible ser libre.

Este modelo pone su fundamento en que lo importante en la vida es lo realmente útil y práctico, y busca su justificación en el utilitarismo social. Es una posición bastante difundida en algunos centros y comités de bioética. En lugar de buscar verdades universales o absolutas, o de tratar de definir una moral válida para todos y para todos los tiempos, recurre a una moral pragmática: la moral del cálculo de la utilidad evaluable, de la relación entre costo y beneficio. El criterio de la utilidad no puede ser nunca el fin último en bioética: siempre debe considerarse y evaluarse el criterio de utilidad teniendo en cuenta la finalidad del acto médico, que es la salud de una persona enferma. El fin de nuestras acciones lo marca de modo último la dignidad de la persona enferma, y no otros tipos de criterios de utilidad. Un ejemplo de esta modelo seria elegir al paciente que más criterios de sobrevida tendría en relación al tratamiento en situaciones de complicación por infección de COVID 19 en la unidad de cuidados intensivos.

Según este modelo, la vida y la sociedad están sujetas a la evolución biológica, sociológica, y los valores morales deben también modificarse de modo evolutivo. El motor es el «egoísmo biológico» que da lugar al derecho y la moral, como expresiones culturales. Desde esta perspectiva, el único valor ético es el que permite mantener el equilibrio evolutivo del ecosistema, en continuo progreso. Todo lo que esté a favor de ese progreso está bien, y lo que comprometa el equilibrio está mal. Este modelo aporta como valor importante la atención al equilibrio evolutivo del ecosistema. Pero hay que tener en cuenta que, para que un acontecimiento se pueda entender como progreso, o en su caso como un retroceso, es necesario hacer referencia a un valor que permita evaluarlo. El planteamiento del supuesto continuo progreso, tomado en forma literal, choca con la experiencia histórica, invalidaría el juicio ético y detendría nuestros esfuerzos por mejorar las situaciones que se nos presenten. Es preciso, por tanto, que el progreso haga referencia a un valor que lo haga auténtico, por el que pueda medirse, y que necesariamente estará por encima de criterios socio-biológicos.

En el panorama cultural actual, la concepción personalista es la que sostiene el primado y la intangibilidad de la persona humana, considerada como valor principal, punto de referencia, fin y no medio. Se parte de la base de que la persona humana es digna en virtud de su propio ser, y no en virtud de lo que tiene. Plantea que desde este fundamento se puede construir una bioética plenamente respetuosa con la dignidad última de la persona humana. Esta dignidad es la que exige el máximo respeto y una efectiva tutela, desde el momento de la concepción al de la muerte natural. Según nuestro parecer, esta concepción responde más plenamente al propio ser del hombre y explica mejor la relación existente entre dignidad de la persona y libertad, no como valores divergentes, sino complementarios. 
principio de libertad y responsabilidad, y d) principio de la sociabilidad y subsidiaridad (26).

\section{Principios personalistas en el manejo de pacientes con COVID 19}

La pandemia por la COVID 19 encarna un ejemplo elocuente donde emergen variedad de problemas que colocaron al mundo en el quiebre de la seguridad económica-sanitaria e incertidumbre ante el peligro del contagio inminente afectando a personas de cualquier condición, profesión y credo. Ningún país estuvo preparado para afrontarla al contar con sistemas de salud desorganizados y economía débil frente a la previsión de recursos materiales y humanos, que ante posibles crisis deben poseer premisas éticas en su asignación (27), priorizando a la persona como centro de la atención y no considerarla sólo con razonamientos de utilidad o subjetividad con ausencia de una concepción holística y poseedora de historia personal (28), encarnado en los pacientes afectados de COVID-19. Además, el surgimiento de litigación entre ética y economía se evidencia cada día más ante el gasto sanitario abrumador y la ausencia de capital moral de quienes la dirigen, motivando por otro lado a las autoridades a una variedad de recaudar fondos para contribuir a superar la falencia de estos.

Desde la bioética personalista el principio sobre la defensa de la vida física del enfermo, con ello el respeto, su defensa y promoción se constituye en el primer imperativo ético del profesional de la salud (PS) ya que el cuerpo no es un simple instrumento sino forma parte de la propia esencia, como base única y necesaria para la existencia en el tiempo y en el espacio. Resultado de este principio cerciora que todo acto sanitario e intervención en el cuerpo es la acción de una persona sobre otra porque uno de ellos es sujeto de intervención sanitaria. De esta manera el cuerpo es coesencial, el fundamento único, por medio del cual la persona se realiza e irrumpe en el tiempo y en el espacio, construye los demás valores, implícito la libertad, la sociabilidad, también el propio proyecto futuro (28).

En la práctica, la interacción entre los actores del acto biomédico, se fue distanciando y diluyendo hasta evitar el acercamiento a los enfermos, los tratamientos eran enviados vía virtual olvidando la visión global del enfermo, emergiendo en el lenguaje de trato "otro caso de COVID-19"; acompañado de una actuación automatizada por no decir mecánica, y donde la tecnología también hizo su aparición, ausente en algunos hospitales e insuficiente en otros por su inmensa demanda, pero que no hablan de la profundidad humana del enfermo y si de la existencia de un reduccionismo evidente (28). Estas razones conducen a pensar que el equipo de salud en general no lo poseía en su cognición como práctica (en unos más que en otros), aunque los códigos de ética les invite a prestar atención de calidad y en su totalidad a los enfermos según necesidades; hubo adopción de posturas reduccionistas tanto lineal como horizontal con supuestos teóricos provenientes de una sociedad invadida por el bienestar y el utilitarismo que pronto hacen olvidar los deberes fundamentales sin intervención de ningún comité de ético-hospitalario para redireccionar las acciones, reclamar guiar y asesorar.

Con respecto a la responsabilidad y libertad de los profesionales de la salud en el acto de atender y cuidar, enrola la dimensión ética, pues en situaciones de crisis hay que tomar decisiones con influencia de manera positiva o negativa en la salud y afrontarla de un modo u otro (25), y es allí donde el profesional actúa y asiste a los pacientes, proporcionándoles una atención humana de orden moral, con seguimiento continuo, con el compromiso de usar los recursos necesarios para lograr el bien de la salud y la de los demás; sin embargo, dicha responsabilidad encuentra obstáculos en el propio sistema, que exige pero no da lo necesario para trabajar de manera armoniosa aún con exigencias públicas en bien del más vulnerable, llegando en ciertos casos a omitir el deber dando órdenes y contraordenes de actuación, sin guías precisas para actuar con eficacia y prontitud.

Entonces, sucedió lo que en muchos países pasó, servicios de emergencia con acumulo de pacientes, desabastecimiento no sólo de recurso material sino también humano, obligados a atender en circunstancias extremas que no facilitaron el buen diagnóstico por ausencia de pruebas, valoración del enfermo con acercamiento continuo y las vidas de los afectados se iban como agua entre las manos, al faltar espacio para el monitoreo de la corporalidad u oxígeno para equilibrar la función respiratoria; mucho menos la aplicación de tratamientos certeros para mejorar la situación de salud. Además, en dichas muertes el cuerpo del fallecido tampoco recibió la atención post morten, menos el trato de objeto moral, más bien sí, como acúmulo de basura, olvidado, que nadie quiere recoger, y las familias sin posibilidad de acercamiento 
a su ser querido, sufriendo también soledad y desamparo sin que nadie le fortalezca en el estado de duelo (28).

Escenario a fuego vivo que debilita el principio de libertad y responsabilidad de forma diferente en los profesionales de la salud como personas libres, en lograr el bien de sí mismo, de las otras personas y de todo el mundo. Entonces el Bien no es logrado a cabalidad, porque se presenta por otro lado la fuerza del deber abstenido de laborar ante los riesgos de la propia vida y la protección de la familia frente a la indiferencia en el abastecimiento de equipos de protección personal (EPP), disyuntiva donde la elección, resulta moralmente admisible (29). Lo cierto es que el principio de libertad y responsabilidad, implica que la libertad toma a cargo responsablemente la vida propia y la ajena (28); para ser libres, se requiere estar vivos, en nombre de la libertad de elección, no se tiene derecho a decidir la supresión de una vida, aspecto que un sistema desorganizado y la presencia de una pandemia facilitó ante la avalancha de enfermos de COVID-19, con muerte en espera de atención.

Incluso la ausencia de la sinergia terapéutica entre médico y paciente (28) porque los segundos reclamaban a gritos atención y los primeros no eran suficientes. Los cuidados indispensables para la vida y la supervivencia quedaron abolidos, como bien personal y social. Ante algunas narrativas de colegas "donde las papas queman", es decir al lado del enfermo de COVID, en las UCI, emergencia, hemodiálisis o servicios improvisados, el grito unánime fue "no estábamos preparados", porque tenemos que recurrir al llanto para que nos dejen EPP, gritar fuerte ante la falta de personal, muerte de médicos, enfermeras, técnicos y parte de sus familias para que recién comprendan la falta que hacen; sumados a los incontables cadáveres copilados en crematorios fétidos y la pregunta salta entre lágrimas ¿en qué momento la sociedad perdió su humanidad? Si para la salud personal, el riesgo de enfrentar el coronavirus es bastante alarmante, también es inaceptable el riesgo de infectar a las familias a causa de la exposición en el lugar de trabajo; lo cierto que en un momento determinado tendremos que dar cuenta de nuestra actuación en respetar la dignidad de cada paciente, sin diferencias personales, enfermedad de base, u otras. Pero sin duda la necesidad imperativa de cuidar de manera especial al equipo de salud y entender que existe una responsabilidad compartida cuando sucede una pandemia (30).
El principio de totalidad o principio terapéutico, haya su fundamento en que el cuerpo es un todo unitario resultado de partes distintas, unificadas en sistemas conectados por la existencia única y personal, con las siguientes exigencias en su aplicación: 1) que se trate de una intervención sobre la parte enferma o la que es causa directa del mal, para salvar al organismo sano; 2) que no existan otras maneras o medios para evitar la enfermedad; 3) que haya una buena posibilidad, proporcionalmente alta, de éxito, y 4) que se dé el consentimiento del paciente, imbuida dentro de la norma de la proporcionalidad de las terapias, es decir al practicar una terapia, ésta se evalúe en el contexto de la totalidad de la persona, que exige cierta proporción entre los riesgos y daños que comporta y los beneficios que procura (28), circunstancias que tuvieron quiebres porque ante el acelerado proceso infeccioso la globalidad de la persona y la proporcionalidad de la terapia no era asequible, por el desabastecimiento de las UCI, y otros de servicios de cuidados críticos debidamente equipados.

Entonces, surgieron las clasificaciones de pacientes: prioridad 1, aquí se encontraban pacientes críticos e inestables; necesitados de monitorización y tratamiento intensivo que no puede ser proporcionado fuera de la UCI; prioridad 2, aquellos con necesidad de monitorización intensiva y con necesidad de intervenciones inmediatas, con altos requerimientos de oxigenoterapia; prioridad 3, pacientes inestables y críticos con pocas posibilidades de recuperarse a causa de su enfermedad de base o de la aguda; y prioridad 4, pacientes cuyo ingreso no está generalmente indicado por obtenerse un beneficio mínimo o improbable (30). Lo cierto es que todos requerían ser atendidos con medidas proporcionadas a la situación de salud y hasta el momento sigue una gran brecha de desatención y olvido ante la escasez de recursos.

Finalmente, el principio de sociabilidad y subsidiariedad, para Sgreccia (28), obliga a todas y cada una de las personas en su propia realización al participar en la realización del bien de sus semejantes como son la promoción de la vida y de la salud. Todo ciudadano se compromete en considerar su propia vida y la de los demás como un bien no sólo personal, sino también social, y compromete a la comunidad a promover la vida y la salud de todos y cada uno, en términos de justicia social, obligando a la comunidad a garantizar todos y cada uno los medios para acceder a los cuidados necesarios, realidad súper débil por parte de quienes gestionan el sistema ya que los servicios de salud no cuentan con planes de 
contingencia ante pandemias, con lo cual emergió el desorden y la improvisación. Por otra parte la presencia de ciudadanos religiosos y civiles solidarios comprometidos con su comunidad sufriente inspirados en la caridad y el bien del prójimo que les condujeron a realizar un sin número de acciones para llevar ayuda a los mismos hospitales, familias y enfermos, mostrando lo que es capaz una sociedad solidaria, comprometida e inspirada con la salud de sus semejantes con ciertos quiebres ante la obligación de guardar cuarentena, con inconciencia ante el autocuidado al no ser su rutina de vida o cambiar de obligaciones para resguardar la salud de los demás $(31,32)$.

\section{CONCLUSIONES}

- Nuestro sistema de salud y la gestión en general en el contexto de la pandemia por COVID 19 debe tener la capacidad de redireccionar sus estrategias basada en sólidas bases antropológicas y éticas, aplicando la justicia distributiva en cuanto a los recursos y buscando el bienestar de sus trabajadores.

- Los profesionales de la salud que se encuentran en primera línea de batalla ante la pandemia deben buscar en todo momento apoyar y consolar a los pacientes que se complican en concordancia con sus derechos inalienables como el de cuidado de la vida y la salud, proporcionándole los medios necesarios para recuperarla en cualquier situación crítica que se encuentre o brindándole el soporte psíquico y espiritual hasta su muerte natural, cuando no se puede curar.

- Como marco normativo ético ante la pandemia recomendamos disponer de los lineamientos para garantizar el ejercicio de la Bioética desde el reconocimiento de los Derechos Humanos, según el Decreto Supremo N ${ }^{\circ}$ 011-2011-JUS, el cual destaca el reconocimiento integral del valor y sentido de la vida humana, así como el respeto de la dignidad humana como fin y no como medio, principios primordiales que podrían aplicarse tanto para los profesionales de las ciencias de la salud como para los pacientes y su interrelación.

\section{Declaración de conflictos de intereses:}

Los autores declaran no tener conflictos de intereses.

\section{Correspondencia:}

Cesar Ñique Carbajal

Correo electrónico: cnique@usat.edu.pe

\section{REFERENCIAS BIBLIOGRÁFICAS}

1. Moreno-Correa SM. La innovación educativa en los tiempos del Coronavirus. Salutem Scientia Spiritus. 2020; 6(1):14-26. (Citado 10 de junio 2020). Disponible en: https://revistas.javerianacali.edu.co/ index.php/salutemscientiaspiritus/article/ view/2290/2863

2. Maguiña C. Reflexiones sobre el COVID-19, el Colegio Médico del Perú y la Salud Pública. Acta Med Peru. 2020;37(1):8-10. Doi: https://doi.org/10.35663/ amp.2020.371.929

3. Gonzalez ME, Feltrer GJ. Aspectos éticos en la toma de decisiones de COVID-19 en Atencion Primaria. Madrid: Sociedad Española de Medicina de Familia y Comunitaria; 2020. (Citado 10 de junio 2020). Disponible en: https://amf-semfyc.com/web/ article_ver.php?id $=2683$

4. Calvo C. Recomendaciones sobre el manejo clínico de la infección por el «nuevo coronavirus» SARSCoV2. An Pediatr (Barc). 2020; 92(4): 241e1-241. e11. Doi: 10.1016/j.anpedi.2020.02.001

5. Valero-Cedeño NJ, Mina-Ortiz JB, Veliz-Castro TI, Merchán-Villafuerte KM, Perozo-Mena AJ. COVID-19: La nueva pandemia con muchas lecciones y nuevos retos. Revisión Narrativa. Kasmera. 2020; 48(1):e48102042020. Doi: 10.5281/zenodo. 3745322

6. Mojica-Crespo R, Morales-Crespo MM. Pandemia COVID-19, la nueva emergencia sanitaria de preocupación internacional: una revisión. Semergen. 2020; 46:65-77. Doi: 10.1016/j.semerg.2020.05.010

7. Domínguez C. El Legado de la Escuela Nacional de Salud Pública del Perú. Lima: Facultad de Medicina, DAMPySP, UNMSM; 2008.

8. Domínguez Barrera C. Reto en la Formación de la Competencia en Salud Pública. Lima: Facultad de Medicina, DAMPySP, UNMSM; 2008.

9. Orantes CA. Salud y enfermedad Personalismo y teoría general de sistemas. Rev ADM. 2010; 67(4):156-162. (Citado 11 de junio 2020) Disponible en: https://www.medigraphic.com/pdfs/adm/od2010/od104c.pdf

10. Domínguez C. Informe por minoría sobre competencia de Salud Pública. Lima: Facultad de Medicina, DAMPySP, UNMSM; 2017.

11. Waldow R. Cuidado humano: la vulnerabilidad del ser enfermo y su dimensión de trascendencia. Index Enferm. 2014; 23(4): 234-238.Doi:10.4321/S113212962014000300009

12. Diaz-Manchay R, Pérez-Loaiza J, CarrascoFernández J, Ñique-Carbajal C. Final de la Vida Humana y COVID 19: Experiencia desgarradora. Rev Cuerpo Med HNAAA. 2020; 13(1):97-98. Doi: 10.35434/rcmhnaaa.2020.131.631

13. Vivar-Mendoza A. COVID-19: La dificultad de enfrentar a un enemigo cambiante. Rev Soc Peru Med Interna. 2020; 33(1):7-9. (Citado 09 de junio de 2020). Disponible en: http://51.79.48.69/index.php/spmi/ 
article/view/503

14. Iserson KV. Healthcare Ethics During a Pandemic. West J Emerg Med. 2020; 21(3). Doi: 10.5811/ westjem.2020.4.47549

15. Antommaria A. Conflicting Duties and reciprocal obligations during a pandemic. J Hosp Med 2020; 5;284-286. doi: 10.12788/jhm.3425

16. Nieves-Cuervo G. Covid, más allá de una pandemia. Salud UIS. 2020. 52(2): 175-6. (Citado 06 de junio de 2020). Disponible en: https://revistas.uis.edu.co/ index.php/revistasaluduis/article/view/10733/10500

17. Comisión Económica para América Latina y el Caribe (CEPAL). América Latina y el Caribe ante la pandemia del COVID-19: efectos económicos $\mathrm{y}$ sociales. Serie: Informe Especial COVID-19 No.1. Comisión Económica para América Latina y el Caribe;2020. (Citado 03 de junio de 2020). Disponible en: https://repositorio.cepal.org/handle/11362/45337

18. Huarcaya-Victoria J. Consideraciones sobre la salud mental en la pandemia de COVID-19. Rev Peru Med Exp Salud Publica. 2020; 37(2): 327-334. (Citado 03 de junio de 2020). Disponible en: https://rpmesp.ins. gob.pe/index.php/rpmesp/article/view/5419

19. Comité de Bioética de España. Declaración del comité de bioética de España sobre el derecho y deber de facilitar el acompañamiento y la asistencia espiritual a los pacientes con covid-19 al final de sus vidas y en situaciones de especial vulnerabilidad. Madrid: Comité de Bioética de España; 2020. (Citado 09 de junio de 2020). Disponible en: http:// assets.comitedebioetica.es/files/documentacion/ CBE_Declaracion_sobre_acompanamiento_ COVID19.pdf

20. Echelini M, Ginarte M. Normativa de emergencia COVID-19 y derechos relacionados con la salud. Rev Hos El Cruce. 2020; 26:9-16.

21. Sonis JD, Kennedy M, Aaronson EL, et al. Humanism in the Age of COVID-19: Renewing Focus on Communication and Compassion. West J Emerg Med. 2020 Apr; 21(3):499-502. DOI: 10.5811/ westjem.2020.4.47596.

22. Sung-Wan K, Kuan-Pin S. Using psychoneuroimmunity against COVID-19. Brain Behav Immun. 2020; 87:1-3. (Citado 09 de junio de 2020). Disponible en: https://www.sciencedirect. com/science/article/pii/S0889159120303913
23. González VJ. Perspectivas de bioética. Ciudad de México: UNAM; 2013.

24. Tomas y Garrido G. Cuestiones actuales de bioética. Navarra, España: EUNSA; 2006.

25. León F. Bioética general y clínica. Santiago de Chile: Fundación Interamericana Ciencia y Vida; 2010.

26. García JJ. Bioética Personalista y Bioética Principialista. Perspectivas. Cuaderno de Bioética XXIV. 2013; 1a:67-76. (Citado 09 de junio de 2020). http://aebioetica.org/revistas/2013/24/80/67.pdf

27. Rubio O, Estella A, Cabre L, et al. Recomendaciones éticas para la toma de decisiones difíciles en las unidades de cuidados intensivos ante la situación excepcional de crisis por la pandemia por covid-19: revisión rápida y consenso de expertos. Medicina intensiva. 2020. Doi: 10.1016/j.medin.2020.04.006

28. Sgreccia E. Manual de bioética I: Fundamentos y ética biomédica. Madrid: Biblioteca de Autores Cristianos; 2014.

29. Fritz Z, Huxtable R, Ibex J, Paton A, Slowthe A, Wilkinson D. Ethical road map through the covid-19 pandemic. BMJ 2020; 369:m2033. doi: 10.1136/bmj. $\mathrm{m} 2033$

30. McConnell D. Balancing the duty to treat with the duty to family in the context of the COVID-19 pandemic. J Med Ethics. 2020; 46(6):360-363. doi: 10.1136/medethics-2020-106250

31. Sánchez I. Lineamientos éticos en la atención de pacientes en una situación de pandemia. Santiago de Chile: Pontificia Universidad Católica de Chile; 2020. (Citado el 19 de mayo de 2020). Disponible en: https://www.uc.cl/site/efs/files/10575/ lineamientos-eticos-en-la-atencion-de-pacientes-enuna-situacion-de- pandemia.pdf

32. Espinoza E, Galán J. Alkdecoa C. Ramasco F. Llamas E. Marco ético pandemia covid-19. Madrid: Sociedad Española de Anestesiología, reanimación y terapéutica del dolor; 2020. (Citado el 09 de junio de 2020). Disponible en: https://www.sedar.es/ images/site/BIBLIOGRAFIA_COVID-19/ Anestesia/DOC_SEDAR_Marco_etico_pandemia coronavirus.pdf

Recibido: 22/06/2020

Aceptado: 27/09/2020 